\title{
Integrated reporting in the public sector
}

Professor Sumit Lodhia, Centre for Sustainability Governance, School of Commerce, University of South Australia

Dr Amanpreet Kaur, Centre for Sustainability Governance, School of Commerce, University of South Australia

Dr Belinda Williams, College of Business \& Economics, University of Tasmania

\author{
Please cite this book as follows: \\ De Villiers, C., Hsiao, P.-C. K. \& Maroun, W. 2020. The Routledge Handbook of \\ Integrated Reporting, Routledge: London, UK.
}

Please cite this chapter as:

Lodhia, S., Kaur, A., and Williams, B. (2020). Current integrated reporting knowledge and future research opportunities - Integrated reporting in the public sector. In C. de Villiers, P.-C. K. Hsiao, and W. Maroun (Eds.), The Routledge Handbook of Integrated Reporting. London: Routledge.

\begin{abstract}
This chapter discusses the potential of integrated reporting for public sector organizations. It emphasises that the public sector is a useful context for exploring integrated reporting, given its societal and sustainability focus. Initially, the focus is on sustainability reporting and the evolution from this form of reporting to integrated reporting. The current status of integrated reporting in the public sector is then discussed. Further studies on integrated reporting and thinking in the public sector are needed to expand our knowledge and understanding of this mechanism and accordingly, the final section outlines future research opportunities.
\end{abstract}

\section{Introduction}

Sustainability is one of the most crucial issues being faced by communities worldwide, and it demands collaborative thinking and action. The concept of sustainability emerged in the 1960s because of substantial environmental degradation caused by imbalanced industrial growth, population growth and poor resource management (Kopnina and Shoreman-Ouimet, 2015). This has led to increasing concerns and awareness about environmental and social impacts of organizational activities including the public sector. There are several critical sustainability issues that are affecting people and the planet, such as climate change, environmental degradation, loss of biodiversity, freshwater scarcity, waste, income 
inequality, unemployment, fairness and justice, health and safety, and poverty (Diesendorf, 2000; OECD, 2001; Schaltegger et al., 2006; Hopwood et al., 2010; UN, 2015). All these issues have drawn social and political attention, and calls have been made to advance the notion of sustainable development.

Consequently, private and public sector organizations are expected to identify and address sustainability issues. Although both of these sectors are equally accountable for their impact on the environment and society, the role and potential of public sector organizations (PSOs) in advancing the notion of sustainable development has been emphasized because they primarily exist to deliver public policy and to promote social welfare (Broadbent and Guthrie, 1992; Ball and Grubnic, 2007; Lewis, 2008; Ball et al., 2014). Ball and Grubnic (2007) recognize 'an affinity between a public sector ethos and the notion of community and fair resource distribution inherent in sustainable development' (p.252). The Global Reporting Initiative's (GRI) Public Sector Supplement asserts that PSOs:

have a civic responsibility to properly manage public goods, resources, and/or facilities in a way that supports sustainable development objectives and promotes the public interest. Public agencies are expected to be open and transparent in their management of public funds and assets. As significant employers, providers of services, and consumers of resources, public agencies also have a major impact on national and global progress towards sustainable development. Given their size and influence, public agencies are expected to lead by example in reporting publicly and transparently on their activities to promote sustainability (GRI, 2005, pp. 7-8).

This implies that the public sector has not only a major role in advancing sustainable development but is also expected to lead by example in relation to transparency and reporting.

In the last two decades, both practitioners and academics have proposed, examined and discussed the emergence of innovative reporting tools in the public sector for enhancing transparency and accountability on sustainability issues (Biondi and Bracci, 2018). The prominent reporting tools that have transformed reporting practices in the public sector 
include social and environmental reporting, sustainability reporting (SR), and more recently integrated reporting (IR) as it brings thinking, planning and reporting together.

IR extends the potential of sustainability reporting and aims to change the mindset of leaders by encouraging them to create value over the short, medium and long term. Moreover, it offers a framework that can enable organizations to manage complex interconnections between people, ideas, finance and the natural environment (CIPFA, 2016). This aim of this chapter is to establish the need for and scope of IR in the public sector. To address this, the notion of sustainability reporting in the public sector is first discussed. We then present an overview of the uptake of IR practice in the public sector through a critical review of existing studies on IR and the final section envisions future research opportunities on IR in the public sector.

\section{Sustainability reporting in the public sector}

Although this chapter focuses on IR practice, this section outlines the state and drivers of sustainability reporting in the public sector as this reporting tool offers the foundation for the emergence of IR. The sustainability reporting mechanisms provide readily available back-end systems, controls and assurance processes, which are critical to support the development of an integrated report, such as, for example, gathering robust 'non-financial' data (CIPFA, 2016). Therefore, before reviewing the state of IR practice, it is important to recognise those practices that have led to the adoption of IR.

In the public sector, sustainability reporting is regarded as:

A public account of an organisation's sustainability performance achieved through a combination of: leadership; strategic partnering; stakeholder engagement; policy outcomes; and the management of the organisation's impacts on the local environment, social well-being and economic prosperity (Ball, 2005, p.4).

Sustainability reporting processes and practices have enabled PSOs to systematically identify and interlink the economic, social and environmental costs and benefits of organizational 
strategies and actions (Lewis, 2008). The use of effective sustainability reporting mechanisms drives organizational changes for sustainability in the public sector (Domingues et al., 2017) and enables organizations to communicate their contribution to sustainable development (Lamprinidi and Kubo, 2008).

The existing literature indicates that sustainability reporting in the public sector is driven by a variety of internal and external factors. Dickinson et al. (2005), in their global study, found PSOs largely produce sustainability reporting to monitor their performance, demonstrate their progress towards sustainability principles, meet stakeholder information demands, comply with regulatory requirements, and manage public relations. Additionally, local context-based studies have provided in-depth insights into regional and cultural drivers of sustainability reporting. For instance, Marcuccio and Steccoli (2005) highlighted that socio-psychological forces (such as willingness to adopt innovative and progressive management techniques) and techno-economic forces (for example, the search for improved financial and non-financial performance through better accountability, reporting and management system) together shape sustainability reporting in Italian local governments.

Most of the extant research indicates that internal influences such as leadership and accountability drive sustainability reporting practices in the public sector. Lodhia et al. (2012), in their study of 19 Australian PSOs, revealed that internal policy requirements and internal stakeholders drove the reporting practices in these agencies. Similarly, Farneti and Guthrie (2009), Bellinger et al. (2011), Lodhia and Jacobs (2013) and Domingues et al. (2017) reported that sustainability reporting practices in the public sector are internally driven. They generally concluded that the internal organizational practices and internal stakeholders provide a more powerful reasoning for sustainability reporting in comparison to adhering to external legitimacy.

Prior literature has also investigated the nature, role and drivers of stakeholder engagement in sustainability reporting in the public sector (Imoniana et al., 2012; Greco et al., 2015; Kaur and Lodhia, 2014, 2016, 2017, 2018, 2019). Greco et al. (2015) assessed the level of engagement achieved by 11 Italian local councils using the AccountAbility (2011) 
framework. They found that stakeholder engagement was limited to informing. In contrast, Kaur and Lodhia $(2017,2018)$ found evidence of effective stakeholder engagement in the sustainability accounting and reporting processes. Similarly, Imoniana et al. (2012) showcased stakeholder involvement in the budgeting process of Brazilian municipalities. The authors found that stakeholders played an important role in monitoring the sustainability indicators of Brazilian municipalities to evaluate their performance.

To communicate sustainability performance to internal and external stakeholders, PSOs use a range of communication media including annual reports, social reports, environmental reports, sustainability reports, web-based reporting, strategy documents, operational plans, council minutes and publicly available scorecards (Marcuccio and Steccolini, 2005; Farneti and Guthrie, 2009; Williams et al., 2011). However, some of these media, including strategy documents, operational plans and council minutes, have limited value for external stakeholders (Farneti and Guthrie, 2009). Moreover, there is a lack of consistency in terms of the use of formal or informal reporting approaches (Williams, 2015).

The use of GRI sustainability reporting guidelines by PSOs has been contested by some researchers. Guthrie and Farneti (2008) explored social and environmental disclosures in Australian PSOs including federal, state and local government bodies. The study revealed that these organizations 'cherry picked' the GRI indicators they wished to disclose, and their reports lacked complete disclosure on the social, environmental and economic impacts of organizational activities. Similar findings were reported by Leeson et al. (2005), Guthrie and Farneti (2008), Tort (2010), Marx and Van-Dyk (2011), Lodhia et al. (2012) and Domingues et al. (2017). The usefulness of the GRI guidelines for PSOs has been questioned as they fail to recognise the importance of specific issues addressed by the public sector, such as educational awareness, which is crucial to many government departments (Guthrie and Farneti, 2008; Lodhia et al., 2012).

Although sustainability reporting in the past has encouraged PSOs to identify and report on their sustainability issues, it has not been very successful in promoting integrated thinking, which is critical in linking thinking, planning and reporting processes. Hence, as discussed 
earlier, IR has emerged as a response to these issues and to transform existing reporting practices. It offers a more comprehensive reporting framework that can instigate collaborative thinking and action on sustainability, and communicate how sustainability norms and principles are embedded, operationalised and delivered by the public sector. The next section presents the need for and state of IR in the public sector.

\section{Integrated reporting in the public sector}

Movement to and benefits of integrated reporting in the public sector

IR and the associated International Integrated Reporting Framework (IIRC Framework) is a new form of reporting that has seen growing interest from PSOs. It is more than simply another report that summarizes information contained in other reports (e.g. the financial report, or the sustainability report). Rather, it seeks to explain how an organization creates value over time by enhancing accountability and stewardship, and promoting understanding of the interdependencies between the organization's capital sources (IIRC, 2013). Although the IIRC Framework was initially seen as being primarily focused on the private sector, the International Integrated Reporting Council (IIRC) considers its applicability to be wider: 'it can also be applied, adapted as necessary, by public sector and not-for-profit organizations' (IIRC, 2013, p.4). The literature supports this statement, arguing that there is great potential in broadening the focus of IR initiatives beyond the private sector (Adams and Simnett, 2011; Bartocci and Picciaia, 2013; Lodhia, 2015).

The literature has examined potential advantages IR could offer the public sector. These advantages include the opportunity for public sector organizations to move beyond historical reporting practices through the recognition and reporting of diverse forms of capital in value creation (Bartocci and Picciaia, 2013; Veltri and Silvestri, 2015; Cohen and Karatzimas, 2015; Katsikas et al., 2017; Montecalvo et al., 2018; Manes-Rossi and Orelli, 2019; Farneti et al., 2019). This could potentially lead to a more inter-connected view of sustainability for the public sector (Guthrie et al., 2017; Monetcalvo et al., 2018; Manes-Rossi, 2018). IR also provides the ability and discretion for public sector organizations to tailor the principlesbased IIRC Framework to tell their individual stories through reporting orientated towards organizational ends (Veltri and Silvestri, 2013; Lodhia, 2015; Oprisor et al., 2016). However, it needs to be noted that the IIRC Framework is not just about IR; it is about organizational 
thinking in an integrated manner, decision-making and actions leading to more integrated processes, and a movement away from silo thinking, often noted in public sector organizations (Bartocci and Picciaia, 2013; Macnab, 2015; Guthrie et al., 2017; Katsikas et al., 2017; Katsikas et al., 2017; Manes-Rossi, 2018).

With the public sector having a broad base of stakeholders, the application of the IIRC Framework also has potential through its focus on stakeholder engagement as a guiding principle, specifically:

An integrated report should provide insight into the nature and quality of the organization's relationships with its key stakeholders, including how and to what extent the organization understands, takes into account and responds to their legitimate needs and interests (IIRC, 2013, p. 5).

By having a stronger focus on stakeholder engagement, the integrated approach could potentially lead to improved provision of useful information to stakeholders and improved accountability outcomes for the public sector (Wild, 2011; Bartocci and Picciaia, 2013; Oprisor et al., 2016; Katsias et al., 2017; Guthrie et al., 2017; Manes-Rossi, 2018; Montecalvo et al., 2018; Manes-Rossi and Orelli, 2019).

Potential challenges to implementing integrated reporting in the public sector Notwithstanding the potential advantages IR can bring to the public sector, it is important to also consider potential challenges discussed in the literature. For example, as the IIRC Framework does not specify measures and metrics, this could potentially lead to inconsistency and lack of comparability between public sector entities, with some arguing for the continued usage of the GRI in preparing integrated reports (Manes-Rossi, 2018). However, without support and agreement by key actors (e.g. public sector organizations, standard setters, professional organizations) (Oprisor et al., 2016), issues of consistency and comparability could potentially occur across all sectors, pointing to the need for an agreed approach towards IR in the public sector. 
Others have raised concerns about the private sector focus of the IIRC Framework development, noting that the level of adaptation required for the public sector is an area that requires further exploration (Oprisor et al., 2016; Manes-Rossi and Orelli, 2019). Guthrie et al. (2017) noted that the public sector is often resistant to change, causing the possible adoption of any new reporting framework to be little more than a cosmetic change to internal management processes. Others have questioned the relevance of reporting against all six capitals in the public sector, arguing for a simplified reporting approach using a combination of IR and popular reporting, but this approach is yet to be examined (Cohen and Karatzimas, 2015).

\section{Potential resources available for the public sector}

In recognition of the implementation challenges facing IR in the public sector, resources have been developed to help explain why and how the public sector should adopt IR. These include the establishment of the Public Sector Pioneer Network ${ }^{i}$ by the IIRC in 2014, in partnership with the Chartered Institute of Public Finance and Accountancy (CIPFA). Resources provided by the network include access to webinars, network meetings, expert insights, resources and shared learning on interpreting the applicability of IR to the public sector. In 2016, the network published a public sector guide specifically focusing on helping leaders understand how integrated thinking and reporting can assist the public sector, through the provision of five case study organizations and their experiences in implementing IR. Other publicly available resources that focus on the benefits of IR include KMPG (2012), PwC (2015), Deloitte (2015), CIMA (2016) and EY (2018).

\section{Review of integrated reporting literature in the public sector}

Studies have noted the importance and the need for research in the public sector, but research examining IR practice is currently lacking (Montecalvo et al., 2015; Dumay et al., 2016; Guthrie et al., 2017). Given the size and influence of the public sector (GRI, 2005), this is an important gap in the literature that requires addressing. An overview of the current empirical contributions to the literature is discussed below, providing insights into the current state of IR in the public sector. 
Few studies have examined types and levels of disclosure in accordance with the IIRC Framework. Two studies (Montecalvo et al., 2018; Farneti et al. 2019) analyzed IR reporting from a state-owned enterprise (SOE) perspective, specifically focusing on New Zealand Post (NZP), a participant in the IIRC's pilot programme. Montecalvo et al. (2018), in applying an institutional theory perspective, examined the influence of IR on sustainability disclosures over the period 2001-2015 in NZP. With adoption of the IIRC Framework in 2012, the study found that IR positively impacted the balance and content of sustainability disclosures, leading to the conclusion that IR enhances sustainability reporting and is a useful accounting technology. Farneti et al. (2019) examined how social disclosures by NZP were influenced by the adoption of the IIRF Framework specifically focusing on intellectual, human, and social and relationship capitals. Through the lens of stakeholder theory, the study found that the IR process led to more meaningful stakeholder engagement, resulting in an increase in more relevant social disclosures. Both studies noted the positive impact IR brought to external reporting at NZP and the potential this may have for SOEs and the public sector in general. However, Montecalvo et al. (2018) raised questions as to whether the IIRF Framework provides a comprehensive framework for all aspects of sustainability, calling for further research in this area.

Other disclosure studies have also examined levels of adherence with the IIRC Framework, noting that prior application of reporting standards and guidelines such as the GRI places organizations in a privileged position in preparing integrated reports (Katsikas et al., 2017). Guthrie et al. (2017) noted how IR can penetrate into public sector organizations through internal levels of change, while Katsikas et al. (2017) found progressive adoption of integrated thinking through management commitment, development of communication channels, provision of professional training and support developed across time. Veltri and Silvestri (2015), in analysing the integrated report of a South African public university, found the level of adherence to the IIRC Framework to be variable, noting a higher focus was required on integrated thinking and more responsiveness to stakeholders. In a further study, Manes-Rossi and Orelli (2019), who examined the IR approaches of three local government councils (Johannesburg, Melbourne and Warsaw), concluded that disclosures were heavily influenced by pressure from main actors, differing across locations in terms of principles and focus adopted. 
A small number of public sector studies have examined the extent to which IR focuses on stakeholder engagement. Farneti et al. (2019), noted more meaningful stakeholder processes occurred following the implementation of IR, as did Katsikas et al. (2017). However, Katsikas et al. (2017) highlighted the need for deeper engagement with all stakeholders, arguing that if stakeholders had an improved comprehension of the linkages between financial and non-financial activities, this would help in alleviating conflicting stakeholder expectations and provide a better understanding of the organization as a whole. Similarly, Manes-Rossi (2018), investigating stakeholder engagement across six public sector 'IR early adopters', found varying levels of engagement, while noting its importance.

In drawing this section to a close, it is clear there is potential for IR in the public sector but further exploration and research is required to overcome a number of challenges presented in this section. This is discussed in the next section.

\section{Future research opportunities on integrated reporting in the public sector}

The studies discussed above have extended the literature on IR in the public sector. They are a useful start but there is much more that could be explored within this sector. The emphasis in this section is on identifying future research opportunities in relation to IR. The context for such studies, comparisons with corporate entities, developments in theorizing, and a focus on integrated thinking (rather than merely reporting) are some areas that could be developed further in relation to IR in the public sector. Furthermore, developments in IR through the auspices of the IIRC, and the link between IR and sustainable development goals, provide a basis for exploring their relevance to public-sector entities. The role of information and communication technologies, assurance, regulation and stakeholder perceptions of IR in the public sector also provide considerable scope for future research.

Our overview of the existing studies on IR indicates that the focus is on Australian, New Zealand, South African and Italian research contexts. Other contexts will need to be investigated. This could include public sector agencies in developing countries, comparing the situation in these contexts to that of entities in the developed world. Country-specific 
studies are needed to gain an in-depth understanding of the current status of public sector integrated thinking and reporting on a global scale. IR and integrated thinking studies at various tiers of the public sector could also provide specific context-based information. For instance, the Australian Commonwealth Sector (Lodhia et al., 2012; Lodhia and Jacobs, 2013), states and local councils (Goswami and Lodhia, 2014) could be studied for IR practices.

Comparisons between public sector entities and companies would also be useful in understanding whether their organizational motives have a role in IR. Corporations have profitability and shareholder wealth maximization as their underlying goal, leading to criticism about whether they are really committed to sustainability issues (Milne and Gray, 2002, 2013). This is of particular concern for IR as some authors claim that the sustainability focus has been replaced by the value focus in recent times (de Villiers et al., 2014). However, with public sector entities, the goal of benefiting the entire society provides scope for a greater focus on sustainability in the IR process.

The theoretical insights informing IR in the public sector also need to be developed further. Theories at different levels (Llewyn, 2003) will provide a lens to explore the empirical data in public sector settings. Research methods used for these studies can also be expanded, with approaches such as focus groups, action research, surveys and quantitative methods accompanying the commonly used interviews and content analysis mechanisms.

There is a need for further studies like that of Guthrie et al. (2017), which explore the integrated thinking process in the public sector. A mere focus on reporting is not sufficient in establishing how IR is embedded into organization processes and established as a practice (Lodhia, 2015). Of particular interest is the role of the various organizational participants in integrated thinking, given that this mechanism attempts to break down organizational silos. For instance, what role do accountants have in facilitating integrated thinking in public sector agencies? Who are the other participants in integrated thinking and reporting in organizations? It would also be worthwhile exploring whether integrated thinking is 
effectively practised in the public sector, the key factors in the success of this process, and the challenges to it.

The various developments in IR facilitated by the IIRC could be assessed within a public sector context in order to gain empirical evidence of actual practices. As an example, the six capitals approach advocated by the IIRC could be used to extend performance management, governance and accountability in the public sector. The use of the IIRC Framework in public sector entities could also be investigated. Public sector entities involved in the IIRC pilot project could also be studied, extending the studies that looked at New Zealand Post (Montecalvo et al., 2018; Farneti et al., 2019).

The 2030 Agenda for Sustainable Development, commonly referred to as Sustainable Development Goals (SDGs), established by the United Nations, will impact organizations, governments and society in general. The public sector will certainly be impacted by these goals and it would be useful to assess the linkage between the SDGs and IR (Adams, 2017) for the public sector. Given that the goal of the public sector is to serve the public interest, the integration of SDGs into public sector systems and processes will be of interest and a useful research endeavour.

Information and communication technologies, especially social media, have transformed corporate communications (Lodhia, 2018) and they also provide potential for IR (Lodhia and Stone, 2017). It would be interesting to observe, for example, the role of social media as a communication tool for IR information and to analyse whether it enhances the effectiveness of IR in the public sector. Issues such as the use of Big Data and the Internet of Things to facilitate integrated thinking and reporting could also be explored.

The assurance of integrated information within the public sector is another issue that could be explored. Such information has to be credible and there is a lack of evidence on the auditing processes involved in this process. Key issues such as who audits such information, the type of assurance statements that are produced and their role in enhancing the credibility of 
integrated information could be investigated. Internal audits in relation to integrated information could also be studied in future research, given the prevalence of mechanisms such as environmental performance audits in the public sector (Rika and Jacobs, 2019).

Some studies have explored stakeholder perceptions of IR in the public sector (Manes-Rossi, 2018; Manes-Rossi and Orelli 2019). Further studies are needed to complement these and similar work in the sustainability accounting and reporting area (Kaur and Lodhia, 2014, 2016, 2017, 2018, 2019). The regulatory aspect of IR in the public sector also needs to be explored. A critical issue that needs addressing is whether this practice should remain voluntary or whether mandatory requirements are needed. An analysis of the views of the various participants in IR is needed to explore this matter. Such studies would provide insights into the effectiveness of voluntary IR and the future of public sector IR regulation.

\section{References}

AccountAbility. (2011). Stakeholder Engagement Standard - Final exposure draft. London, UK: AccountAbility.

Adams, C. A. (2017). The Sustainable Development Goals: Integrated thinking and the integrated report. IIRC and ICAS.

Adams, S, and Simnett, R. (2011). Integrated reporting: an opportunity for Australia not-forprofit sector. Australian Accounting Review, 21(3), 292-301.

Ball, A. (2005). Advancing sustainability reporting: An agenda for public service organisations: A discussion paper. London: Chartered Institute of Public Finance and Accountancy.

Ball, A, and Grubnic, S. (2007). Sustainability accounting and accountability in the public sector. In J. Unerman, J. Bebbington, and B. O'Dwyer (Eds.), Sustainability Accounting and Accountability (pp. 243-265). London: Routledge.

Ball, A., Grubnic, S, and Birchall, J. (2014). Sustainability accounting and accountability in the public sector. In J. Beggington, J. Unerman, and B. O’Dwyer (Eds.), Sustainability Accounting and Accountability (pp. 176-196). London: Routledge.

Bartocci, L, and Picciaia, F. (2013). Towards integrated reporting in the public sector. In C. Busco, M. L. Frigo, A. Riccaboni, and P. Quattrone (Eds.), Integrated reporting: concepts and cases that redefine corporate accountability (pp. 191-204). Springer. 
Bellringer, A., Ball, A, and Craig, R. (2011). Reasons for sustainability reporting by New Zealand local governments. Sustainability Accounting, Management and Policy Journal, 2(1), 126-138.

Biondi, L, and Bracci, E. (2018). Sustainability, Popular and Integrated Reporting in the Public Sector: A Fad and Fashion Perspective. Sustainability, 10(9), 3112.

Birney, A., Clarkson, H., Madden, P., Porritt, J, and Tuxworth, B. (2010). Stepping up: a framework for public sector leadership on sustainability. London: Forum for the Future.

Broadbent, J, and Guthrie, J. (1992). Changes in the public sector: A review of recent "alternative" accounting research. Accounting, Auditing \& Accountability Journal, 5(2), $3-31$.

Chartered Institute of Chartered Accountants (CIMA). (2016). Integrated reporting in the public sector. Available at: https://integratedreporting.org/resource/cima-integratedreporting-in-the-public-sector/ (Accessed: 22 May 2019).

Chartered Institute of Public Finance and Accountancy (CIPFA). (2016). Integrated thinking and reporting: Focusing on value creation in the public sector - An introduction for leaders. Available at: https://integratedreporting.org/wpcontent/uploads/2016/09/Focusing-on-value-creation-in-the-public-sector-_vFINAL.pdf (Accessed: 23 October 2019).

Cohen, S., and Karatzimas, S. (2015). Tracing the future of reporting in the public sector: introducing integrated popular reporting. International Journal of Public Sector Management, 28(6), 449-460.

de Villiers, C., Rinaldi, L., and Unerman, J. (2014). Integrated Reporting: Insights, gaps and an agenda for future research. Accounting, Auditing \& Accountability Journal, 27(7), 1042-1067.

Deloitte. (2015). Integrated Reporting as a driver for Integrated Thinking? Available at: https://www2.deloitte.com/content/dam/Deloitte/nl/Documents/ris k/deloitte-nl-riskintegrated-reporting-a-driver-for-integratedthinking.pdf (Accessed: 23 May 2019).

Dickinson, D., Leeson, R., Ivers, J, and Karic, J. (2005). Sustainability reporting by public agencies: International uptake, forms and practice. Victoria, Australia: The Centre for Public Agency Sustainability Reporting.

Diesendorf, M. (2000). Sustainability and Sustainable Development. In D. Dunphy, J. Benveniste, A. Griffiths, and P. Sutton (Eds.), Sustainability: The corporate challenge of the 21st century (pp. 19-37). Sydney: Allen \& Unwin. 
Domingues, A. R., Lozano, R., Ceulemans, K, and Ramos, T. B. (2017). Sustainability reporting in public sector organisations: Exploring the relation between the reporting process and organisational change management for sustainability. Journal of Environmental Management, 192, 292-301.

Dumay, J., Bernardi, C., Guthrie, J, and Demartini, P. (2016). Integrated reporting: a structured literature review. Accounting Forum, 40(3), 166-185.

EY. (2018). EY's Excellence in Integrated Reporting Awards. A survey of the integrated reports of South Africa's top 10 state-owned entities. Available at: https://integratedreportingsa.org/ey-excellence-in-integrated-reporting-awards-2018/ (Accessed: 22 May 2019).

Farneti, F, and Guthrie, J. (2009). Sustainability reporting by Australian public sector organizations: Why they report. Accounting Forum, 33(2), 89-98.

Farneti, F., Casonato, F., Montecalvo, M, and de Villiers, C. (2019). The influence of Integrated Reporting and stakeholder information needs on the disclosure of social information in a state-owned enterprise. Meditari Accountancy Research, 27(4), 556579.

Friedman, M. (2007). The social responsibility of business is to increase its profits. In W. C. Zimmerli, M. Holzinger, and K. Richter (Eds.), Corporate Ethics \& Corporate Governance (pp. 173-178). Switzerland: Springer.

Global Reporting Initiative (GRI). (2005). Sector supplement for public agencies. Amsterdam: GRI.

Goswami, K, and Lodhia, S. (2014). Sustainability disclosure patterns of South Australian local councils: a case study. Public Money \& Management, 34(4), 273-280.

Gray, R. H. (2001) Accounting for the environment. London: Sage Publications.

Greco, G., Sciulli, N, and D’Onza, G. (2015). The Influence of Stakeholder Engagement on Sustainability Reporting: Evidence from Italian local councils. Public Management Review, 17(4), 465-488.

Guthrie, J, and Farneti, F. (2008). GRI Sustainability Reporting by Australian Public Sector Organizations. Public Money \& Management, 28(6), 361-366.

Guthrie, J., Manes-Rossi, F, and Orelli, R.L. (2017). Integrated Reporting and integrated thinking in Italian public sector organisations. Meditari Accountancy Research, 25(4), 553-573. 
Hopwood, A., Unerman, J, and Fries, J. (2010). Introduction to the accounting for sustainability case studies. In A. Hopwood, and J. Unerman (Eds.), Accounting for Sustainability: Practical Insights (pp. 1-28). London: Routledge.

IIRC and CIPFA. (2016). Focusing on value creation in the public sector. Available at: https://integratedreporting.org/resource/focusing-on-value-creation-in-the-publicsector/ (Accessed: 22 May 2019).

IIRC. (2013). The International <IR > Framework. Available at: http://integratedreporting.org/resource/international-ir-framework/ (Accessed: 15 May 2019).

Imoniana, J. O., Domingos, L. C., Soares, R. R., and Tinoco, J. E. P. (2012). Stakeholders' engagement in sustainability development and reporting: Evidence from Brazil. African Journal of Business Management, 6(42), 10634-10644.

Katsikas E., Manes-Rossi, F., and Orelli R. (2017). Towards Integrated Reporting Accounting Change in the Public Sector. Switzerland: Springer.

Kaur, A., and Lodhia, S. (2014). The state of disclosures on stakeholder engagement in sustainability reporting in Australian local councils. Pacific Accounting Review, 26(1/2), 54-74.

Kaur, A., and Lodhia, S. (2016). Influences on stakeholder engagement in sustainability accounting and reporting: A study of Australian Local Councils. Corporate Responsibility \& Stakeholding, 10, 105-129.

Kaur, A., and Lodhia, S. (2017). The Extent of Stakeholder Engagement in Sustainability Accounting and Reporting: Does Empowerment of Stakeholders Really Exist? Modern Organisational Governance, 12, 129-145.

Kaur, A., and Lodhia, S. (2018). Stakeholder engagement in sustainability accounting and reporting: A study of Australian local councils. Accounting, Auditing \& Accountability Journal, 31(1), 338-368.

Kaur, A., and Lodhia, S. (2019). Key issues and challenges in stakeholder engagement in sustainability reporting: A study of Australian local councils. Pacific Accounting Review, 31(1), 2-18.

Kopnina, H., and Shoreman-Ouimet, E. (2015). Introduction: The emergence and development of sustainability. In H. Kopnina, and E. Shoreman-Ouimet (Eds.), Sustainability: key issues (pp. 3-24). Routledge.

KPMG. (2012), Integrated reporting. Performance insight through better business reporting. Available at: www.kpmg.com/AU/en/IssuesAndInsights/ArticlesPublications/ Better- 
Business-Reporting/Documents/integrated-reporting-issue-2.pdf (Accessed: 22 May 2019).

Lamprinidi, S., and Kubo, N. (2008). Debate: The Global Reporting Initiative and public agencies. Public Money \& Management, 28, 326-329.

Laughlin, R. C. (1991). Environmental disturbances and organizational transitions and transformations: some alternative models. Organization Studies, 12(2), 209-232.

Leeson, R., Ivers, J., and Dickinson, D. (2005). Sustainability reporting by the public sector: Momentum changes in the practice, uptake and form of reporting by public agencies. Accountability Forum, 8, 12-21.

Lewis, T. (2008). Debate: Public sector sustainability reporting-Implications for accountants. Public Money \& Management, 28(6), 329-331.

Llewelyn, S. (2003). What counts as 'theory' in qualitative management and accounting research? Introducing five levels of theorizing. Accounting, Auditing \& Accountability Journal, 16(4), 662-708.

Lodhia, S. (2015). Exploring the transition to integrated reporting through a practice lens: an Australian customer owned bank perspective. Journal of Business Ethics, 129(3), 585598.

Lodhia, S. (2018). Is the medium the message? Advancing the research agenda on the role of communication media in sustainability reporting. Meditari Accountancy Research, 26(1), 2-12.

Lodhia, S., and Jacobs, K. (2013). The practice turn in environmental reporting: A study into current practices in two Australian commonwealth departments. Accounting, Auditing \& Accountability Journal, 26(4), 595-615.

Lodhia, S., and Stone, G. (2017). Integrated reporting in a social media and internet communication environment: conceptual insights. Australian Accounting Review, 27(1), 17-33.

Lodhia, S., Jacobs, K, and Park, Y. J. (2012). Driving public sector environmental reporting: the disclosure practices of Australian Commonwealth departments. Public Management Review, 14(5), 631-647.

Macnab, A. (2015). Debate: Would outcome costing and integrated reporting link resources to strategy in the public sector? Public Money \& Management, 35(6), 399-400.

Manes-Rossi, F. (2018). Is integrated reporting a new challenge for public sector entities? African Journal of Business Management, 12(7), 172-187. 
Manes-Rossi, F., and Orelli. R. L. (2019). New frontiers for local government reporting: learning by pioneers. In M. S. Chiucchi, and P. Demartini (Eds.), Qualitative research in intangibles, intellectual capital and integrated reporting practices: Opportunities, criticalities and future perspectives (pp. 13-40). Roma, Marzo: RomaTre Press.

Marcuccio, M., and Steccolini, I. (2005). Social and environmental reporting in local authorities: a new Italian fashion? Public Management Review, 7(2), 155-176.

Marx, B., and Van-Dyk, V. (2011). Sustainability reporting at large public sector entities in South Africa. South African Journal of Accounting Research, 25(1), 103-127.

Milne, M. J, and Gray, R. H. (2014). W(h)ither Ecology? The Triple Bottom Line, the Global Reporting Initiative, and Corporate Sustainability Reporting. Journal of Business Ethics, 118(1), 13-29.

Montecalvo, M., Farneti, F, and de Villiers, C. (2018). The potential of integrated reporting to enhance sustainability reporting in the public sector. Public Money \& Management, 38(5), 365-374.

Oprisor, T., Tudor, A. T., and Silvia, N. C. (2016). The integrated reporting system: a new accountability enhancement tool for public sector entities. Audit financiar, 7(139), 749762.

Organisation for Economic Cooperation and Development (OECD). (2001). Sustainable Development: Critical Issues. Paris: OECD Publishing.

PricewaterhouseCoopers (PwC). (2015). Implementing integrated reporting. Available at: https://www.pwc.com/gx/en/auditservices/publications/assets/pw c-ir-practicalguide.pdf (Accessed: 22 May 2019).

Rika, N., and Jacobs, K. (2019). Reputational risk and environmental performance auditing: A study in the Australian commonwealth public sector. Financial Accountability \& Management, 35(2), 182-198.

Rinaldi, L., Unerman, J., and de Villiers, C. (2018). Evaluating the integrated reporting journey: insights, gaps and agendas for future research. Accounting, Auditing \& Accountability Journal, 31(5), 1294-1318.

Schaltegger, S., Bennett, M., and Burritt, R. (2006). Sustainability accounting and reporting: Development, linkages and reflection-An introduction. In S. Schaltegger, M. Bennett, and R. Burritt (Eds.), Sustainability Accounting and Reporting (pp. 1-33). Dordrecht, The Netherlands: Springer.

Stubbs, W., and Higgins, C. (2014). Integrated reporting and internal mechanisms of change. Accounting, Auditing and Accountability Journal, 27(7), 1068-1089. 
Tort, L. E. (2010). GRI reporting in public agencies. Amsterdam, The Netherlands: Global Reporting Initiative.

United Nations (UN). (2015). Transforming our World: The 2030 Agenda for Sustainable Development. United Nations.

Veltri, S., and Silvestri, A. (2015). The Free State University integrated reporting: a critical consideration. Journal of Intellectual Capital, 16(2), 443-462.

Wild, S. (2011). Public sector accountability for cultural assets: An integrated reporting approach. International Journal of Environmental, Cultural, Economic and Social Sustainability, 7(5), 379-390.

Williams, B. R. (2015). Reporting on sustainability by Australian councils-a communication perspective. Asian Review of Accounting, 23(2), 186-203.

Williams, B. R., Wilmshurst, T., and Clift, R. (2011). Sustainability reporting by local government in Australia: current and future prospects. Accounting Forum, 35(3), 176186.

i https://integratedreporting.org/ir-networks/public-sector-pioneer-network/ 